Final version appears as: Superconductivity and Magnetism in Silicon and Germanium Clathrates, J. H. Ross, Jr. and Y. Li, in Nanoscale Magnetic Materials and Applications, ed. J. P. Liu, E. Fullerton, O. Gutfleisch, and D. Sellmyer (Springer, 2009) pp. 105-121. (c) Springer-Verlag US. DOI: $10.1007 / 978-0-387-85600-144$

\title{
Superconductivity and Magnetism in Silicon and Germanium Clathrates
}

Joseph H. Ross Jr.

Department of Physics, Texas A\&M University, College Station TX 77843-4242

Yang Li

Department of Engineering Science and Materials, University of Puerto Rico at Mayaguez, Mayaguez, PR 00681-9044

\begin{abstract}
Clathrates are materials containing closed polyhedral cages stacked to form crystalline frameworks. With $\mathrm{Si}, \mathrm{Ge}$, and $\mathrm{Sn}$ atoms populating these frameworks, a wide variety of electronic and vibrational properties can be produced in these materials, by substitution upon framework sites or through incorporation of ions in cage-center positions. Commonly-formed structures include the type I, type II, and chiral clathrate types, whose properties will be described here. $\mathrm{Ba}_{8} \mathrm{Si}_{46}$ with the type-I structure has been found to exhibit superconductivity with $T_{c}$ as high as $9 \mathrm{~K}$. The enhanced $T_{c}$ in this compound has been shown to arise predominantly from very sharp features in the electronic densities of states associated with the extended $s p^{3}$ bonded framework. Atomic substitution can tailor these electronic properties, however the associated disorder has been found to inevitably lower the $T_{c}$ due to the disrupted continuity of the framework. Efforts to produce analogous Ge-based superconductors have not been successful, due to the appearance of spontaneous vacancies, which also serve to disrupt the frameworks. The formation of these vacancies is driven by the Zintl mechanism, which plays a much more significant role for the structural stability of the Ge clathrates. The sharp density of states features in these extended framework materials may also lead to enhanced magnetic features, due to conduction-electron mediated coupling of substituted magnetic ions. This has led to magnetic ordering in $\mathrm{Fe}$ and $\mathrm{Mn}$-substituted clathrates. The largest number of clathrates exhibiting magnetic behavior has been produced by substitution of Eu on cage-center sites, with a ferromagnetic $T_{c}$ as high as $38 \mathrm{~K}$ observed in such materials.
\end{abstract}

\section{Introduction.}

Clathrates containing crystalline frameworks of group-IV semiconductors have attracted considerable interest in recent years for their variety of electronic and vibrational properties. Like carbon-based fullerenes, silicon, germanium, and tin also form polyhedral cage structures. However unlike fullerenes, the heavier group-IV elements form $s p^{3}$-bonded connected structures periodic in three dimensions. Intermediate between the disconnected fullerenes and the tetrahedral diamond structure, these materials have a number of unique properties. In this review we discuss the electronic and vibrational properties of these framework materials, specifically as they relate to the appearance of superconductivity and magnetism.

While closed-cage materials of all types can be denoted as clathrates, the class of group-IV clathrates generally refers to the set of materials that share a common structure with the hydrate clathrates. The latter are crystalline materials such as methane hydrate, $8 \mathrm{CH}_{4} \bullet 46 \mathrm{H}_{2} \mathrm{O}$, in which the water molecules form a framework enclosing individual methane molecules in a regular 
array. Methane clathrate is naturally occurring when natural gas combines with seawater at pressures of the ocean floor. The potential for useful energy reserves or of greenhouse gas emissions from such formations is one of the reasons for intensive interest in such materials. Several recent reviews [1-4] describe the features of the hydrate clathrates.

Jeffrey [5] developed a naming convention for the hydrate clathrates; by this labeling scheme "Type I" and "Type II" are the most commonly observed structures. These are illustrated in Figures 1 and 2. These structures feature three-dimensional tessellations that completely fill space with polyhedral cages, such as the dodecahedron and tetrakaidecahedron that make up the type-I structure shown in Figure 1. In the hydrate clathrates, the vertices of these polyhedra are water oxygens, while small molecules fill the closed cages. Figures 1 and 2 show silicon clathrates for which the framework is a fourfold-bonded Si-atom network. Another set of materials sharing identical structural characteristics is the clathrasils [6], in which the crystalline framework is constructed of $\mathrm{SiO}_{2}$, rather than $\mathrm{H}_{2} \mathrm{O}$.

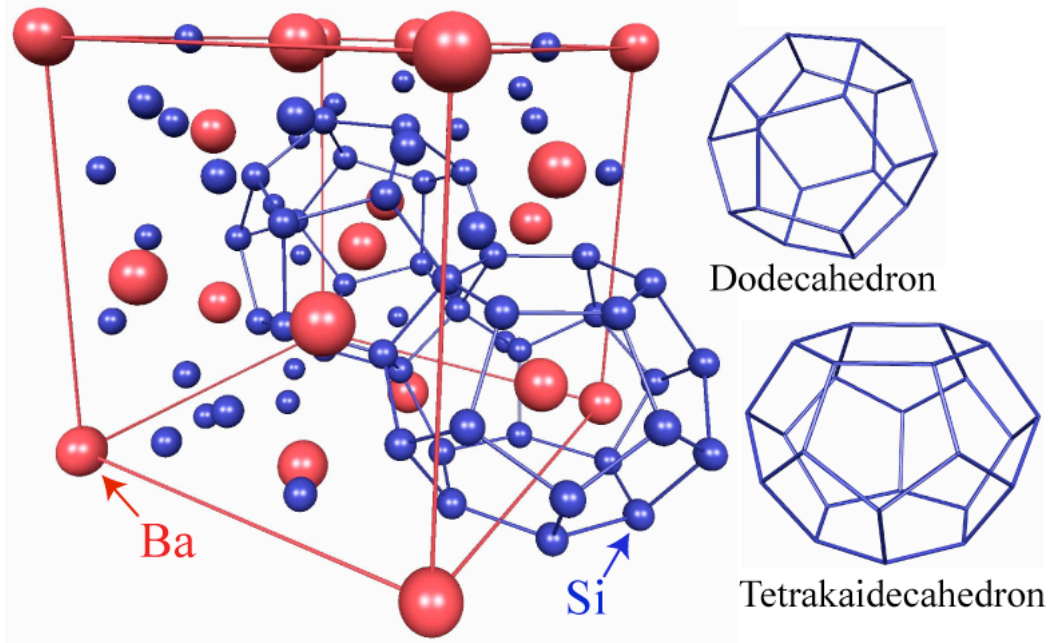

Figure 1: Type-I clathrate structure, with $\mathrm{Si}$ and $\mathrm{Ba}$ atoms labeled according to the $\mathrm{Ba}_{8} \mathrm{Si}_{46}$ composition. Also shown are the two basic cages forming the $\mathrm{Si}_{46}$ framework for the structure (space group $\operatorname{Pm} \overline{3} m$, \#223), along with the cubic unit cell. The $\mathrm{Si}_{46}$ framework is a closed network involving all Si sites; only two of the polyhedra are shown connected for clarity. 


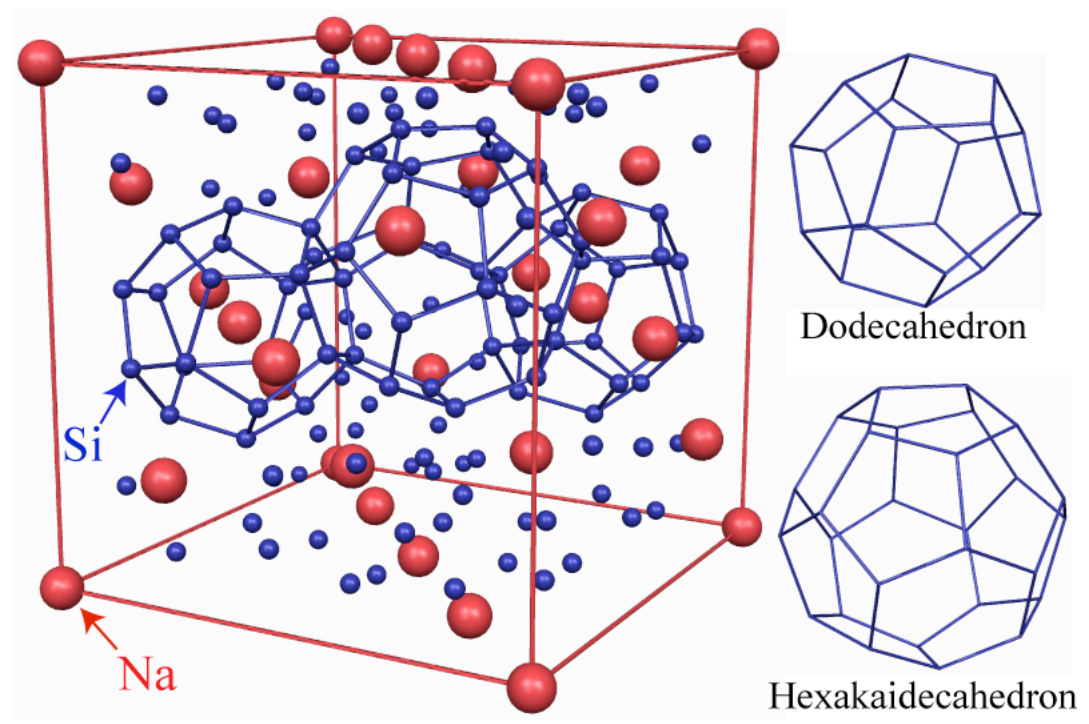

Figure 2: Type-II clathrate structure, illustrated along with the two cages that make up the closed network. Inside the cubic unit cell a central hexakaidecahedron is shown connected to two of its neighboring dodecahedra. Atom labels correspond to $\mathrm{Na}_{16} \mathrm{Si}_{136}$; the $8 b$ site the filling large cage is shown unoccupied. Space group is $F d \overline{3} m$ (\#227).

The silicon clathrates were first synthesized in 1965 [7], when type-I $\mathrm{Na}_{8} \mathrm{Si}_{46}$ and type-II $\mathrm{Na}_{x} \mathrm{Si}_{136}$ were prepared. A large number of related compositions have since been synthesized, including those with frameworks of $\mathrm{Ge}$ and $\mathrm{Sn}$, and cage-filling atoms including $\mathrm{Na}, \mathrm{K}, \mathrm{Rb}, \mathrm{Sr}, \mathrm{Ba}, \mathrm{Te}, \mathrm{Cl}$, $\mathrm{Br}, \mathrm{I}, \mathrm{Eu}, \mathrm{H}_{2}$. Aside from column-IV elements, the framework may be substituted from columns II through VI, a few examples being type-I $\mathrm{Sr}_{8} \mathrm{Al}_{16} \mathrm{Ge}_{30}$ [8], $\mathrm{Ba}_{8} \mathrm{Ga}_{18} \mathrm{Sb}_{2} \mathrm{Ge}_{26}$ [9], $\mathrm{Te}_{8}\left(\mathrm{Si}_{38} \mathrm{Te}_{8}\right)$ [10] and $\mathrm{Cs}_{8} \mathrm{Zn}_{4} \mathrm{Sn}_{42}$ [11], or type-II $\mathrm{Ba}_{16} \mathrm{Ga}_{32} \mathrm{Sn}_{104}$ [12]. Furthermore, several late transition metal elements have been substituted on the Si and Ge frameworks [13], while Si and Ge type-II clathrates can also be formed as empty frameworks [14,15], by driving $\mathrm{Na}$ out of the filled cages or out of an intermediate product, respectively.

Closely related structural types not observed among the hydrate clathrates include the low temperature stable structure found in $\alpha-\mathrm{Ba}_{8} \mathrm{Ga}_{16} \mathrm{Sn}_{30}$ [8] and $\alpha-\mathrm{Eu}_{8} \mathrm{Ga}_{16} \mathrm{Ge}_{30}$ [16], a cubic structure closely related to the type-I structure stable at high temperatures in both of these materials (type I corresponding to the $\beta$-phases). This structure has also been called "clathrate VIII," as an addition to the seven structure types originally identified among hydrate clathrates. The chiral clathrate structure, originally discovered as the structure of $\mathrm{Ba}_{6} \mathrm{In}_{4} \mathrm{Ge}_{21}$ [17], has been identified to form several silicon and germanium compounds, generally in combination with barium, as in the binaries $\mathrm{Ba}_{6} \mathrm{Si}_{25}$ [18] and $\mathrm{Ba}_{6} \mathrm{Ge}_{25}$ [19]. Tin-based chiral clathrates can be formed with alkali metals, for example $\mathrm{K}_{6} \mathrm{Sn}_{25}$ [20]. A member of the chiral space group \#213 $\left(P 4_{1} 23\right)$, the chiral clathrate structure features polyhedral cages arranged in a three-dimensional network of interlinked helices (Figure 3). Aside from the single type of closed cage, which encloses the cation occupying the $8 c$ site, the structure also features two additional cation sites in open regions of the cell. In addition, two of the six framework sites (representing 8 of the 25 framework atoms per formula unit) are only threefold coordinated to other framework atoms, as opposed to the fourfold coordination uniformly observed in all other clathrates discussed here. At times this structure has been termed type IX or type III (although a different hydrate clathrate structure also has been labeled type III); here the designation "chiral clathrate" will be used. 


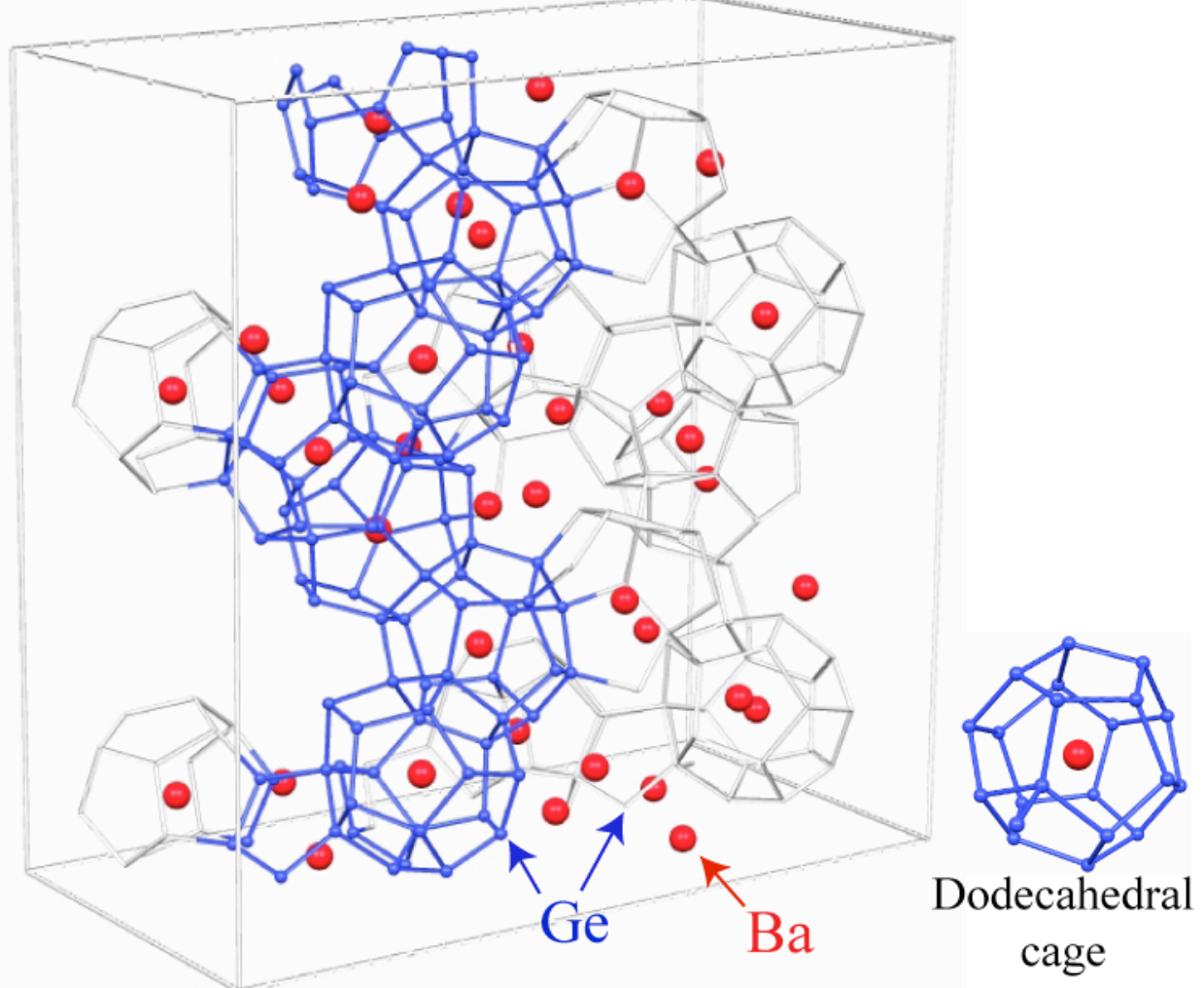

Figure 3: Chiral clathrate structure, as observed in $\mathrm{Ba}_{8} \mathrm{Ge}_{25}$ [18]. A $2 \times 2 \times 1$ raft of cubic cells is illustrated at left. Large spheres are $\mathrm{Ba}$, with connected framework composed of $\mathrm{Ge}$ atoms. One helical grouping of framework cages has been highlighted for clarity, however all cages are identical, forming somewhat irregular dodecahedra.

\section{Superconductivity in $\mathrm{Si}_{46}$ Clathrates}

Roy [21] initially searched for superconductivity in type-I and type-II Na-Si clathrates, however these original silicon clathrates were found not to be superconducting. A few years later the typeI composition $\mathrm{Na}_{2.9} \mathrm{Ba}_{4.5} \mathrm{Si}_{46}$ was prepared and shown to be superconducting with $T_{c}$ near $4 \mathrm{~K}$ [22]. Similarly, the K- and Ba-filled analog was found to have $T_{c}=3.2 \mathrm{~K}$ [23]. Advances in synthesis, in particular high-pressure methods, led to the preparation of $\mathrm{Ba}_{8} \mathrm{Si}_{46}$ for which the alkali metals were replaced completely by $\mathrm{Ba}$ [24]. This composition achieves a superconducting $T_{c}=8 \mathrm{~K} . \mathrm{Ba}_{8} \mathrm{Si}_{46}$ prepared with a slight deficit of $\mathrm{Ba}$ was found to have $T_{c}$ as high as $9.0 \mathrm{~K}$ [25], which is a high-water mark for superconducting transition temperatures among $s p^{3}$-bonded clathrates.

Further advances in synthesis have included the production of single crystals of $\mathrm{Ba}_{7.6} \mathrm{Si}_{46}$ [26], however with no increase in $T_{c}$ of this material. Single crystals of the $\mathrm{Na}_{2} \mathrm{Ba}_{6} \mathrm{Si}_{46}$ clathrate have also been produced, and a crystallographic study confirming the ordered structure of this material, with $\mathrm{Na}$ ions occupying the smaller dodecahedral cages, and $\mathrm{Ba}$ ions the larger tetrakaidecahedral cages, surrounded by a fully-populated $\mathrm{Si}_{46}$ framework [27].

\section{Rattler Atoms and Narrow Bands.}


Among the distinctive features commonly observed in the clathrates is low-frequency Einsteinlike phonon modes. Generally associated with ions loosely held within their encapsulating cages, such modes can be observed by various techniques, including Raman scattering [28] or detection of the displacements of the encapsulated ions via x-ray [29] or neutron [30] crystallography. Einstein modes with energies corresponding to approximately $80 \mathrm{~K}$ have been reported for $\mathrm{Ba}_{8} \mathrm{Si}_{46}$ [31], between $30 \mathrm{~K}$ and $60 \mathrm{~K}$ for type- $\mathrm{Eu}_{8} \mathrm{Ga}_{16} \mathrm{Ge}_{30}, \mathrm{Sr}_{8} \mathrm{Ga}_{16} \mathrm{Ge}_{30}$, and $\mathrm{Ba}_{8} \mathrm{Ga}_{16} \mathrm{Ge}_{30}$ [30], and 45 to $60 \mathrm{~K}$ in type- $\mathrm{Cs}_{8} \mathrm{Ga}_{8} \mathrm{Sn}_{38}$ [32], with similar small values obtained for many other clathrate materials.

Slack [33] originally suggested the idea that the "rattling" of encapsulated ions may contribute to low observed thermal conductivities, a feature of great current interest due to potential thermoelectric applications for semiconducting compositions of these materials. Similar behavior is observed in other cage-type materials, particularly the skutterudites [34]. Much effort has been devoted to understanding such behavior in type-I materials in particular, for which the larger tetrakaidecahedral cages afford room for smaller ions to displace to off-center positions within the cage. A recent work [35] gave direct evidence for a very low frequency $(450 \mathrm{MHz} \sim 20 \mathrm{mK}$ ) mode attributed to tunneling between such off-center positions in $\mathrm{Eu}_{8} \mathrm{Ga}_{16} \mathrm{Ge}_{30}$. Furthermore glasslike thermal conductivity with $T^{2}$ temperature dependence has been observed in $\mathrm{Eu}_{8} \mathrm{Ga}_{16} \mathrm{Ge}_{30}$ and $\mathrm{Sr}_{8} \mathrm{Ga}_{16} \mathrm{Ge}_{30}$ [36], at temperatures of order a few kelvins. The standard explanation for such behavior is phonon tunnel centers spread over a wide range of energies. The source of this energy spread is not entirely clear, however there is additional spectroscopic evidence for distributed behavior [37,38], which may be related to intrinsic framework-site disorder due to mixed atomic occupation in the alloyed clathrates such as $\mathrm{Sr}_{8} \mathrm{Ga}_{16} \mathrm{Ge}_{30}$.

Note that other mechanisms may also affect the thermal conductivity; in particular a large electron-phonon coupling parameter has been argued to be important in the Ba-Ge type-I clathrates $[39,40]$. However it is clear that there is a large density of phonon modes at low frequencies, which can potentially affect the superconducting behavior in these systems. Some of the observed behavior may relate to the mixed site occupancy in alloyed clathrates, however even in $\mathrm{Na}_{8} \mathrm{Si}_{46}$, amorphous-like thermal conductivity has been observed at low temperatures [41].

The electronic properties of the superconducting silicon clathrates feature sharp electron density of states peaks at or near the Fermi energy $\left(E_{F}\right)$. This is illustrated in Figure 4 [42], where a particularly sharp peak can be seen in the calculated density of states at the position of $E_{F}$ for $\mathrm{Ba}_{8} \mathrm{Si}_{46}$. It was noted in the original report $[22,43]$ that a similar behavior may hold for $\mathrm{Na}_{2} \mathrm{Ba}_{6} \mathrm{Si}_{46}$. Photoemission [44] and NMR [45] experiments have confirmed the large $g\left(E_{F}\right)$ in these cases. 


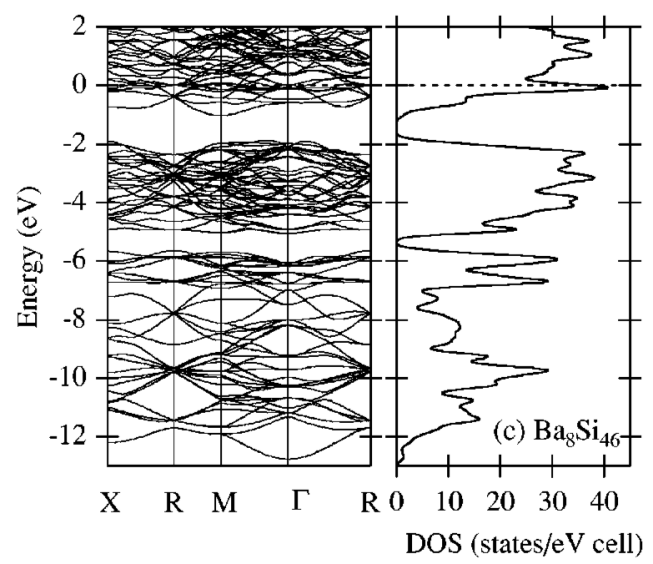

Figure 4: Band structure and electron density of states for type-I $\mathrm{Ba}_{8} \mathrm{Si}_{46}$, calculated using an ab initio pseudopotential method, from [42]. Horizontal dashed line represents $E_{F}$. States are measured per cell, which contains the standard formula unit $\mathrm{Ba}_{8} \mathrm{Si}_{46}$. (C) 2000 American Physical Society.

Aside from the behavior near $E_{F}$, it is also a general feature of the silicon and germanium clathrates that the bands are narrowed, and $g(E)$ enhanced, compared to the corresponding diamond-structure semiconductors. Figure 5 shows a comparison of calculated electronic structures for empty silicon and germanium clathrates [46]. These feature larger band-gaps than diamond-structure silicon or germanium. This result follows the general expectation of expanded structure leading to reduced hybridization and hence a smaller bandwidth. This mechanism is demonstrated in $A_{3} \mathrm{C}_{60}$ fullerides $\left(A=\right.$ alkali metal atom), for which $g\left(E_{F}\right)$ increases monotonically with cell size as the cation is changed, decreasing the overlap between fullerene molecules. An increase in superconducting $T_{c}$ that is also monotonic in cell size tracks the $g\left(E_{F}\right)$ increase [47]. For example, in $\mathrm{Rb}_{2} \mathrm{CsC}_{60}, T_{c}=31 \mathrm{~K}$, while $g\left(E_{F}\right)$ is 24 states $/ \mathrm{eV}$ per $\mathrm{C}_{60}$ molecule, comparable to the height of the peak seen in Figure 4.

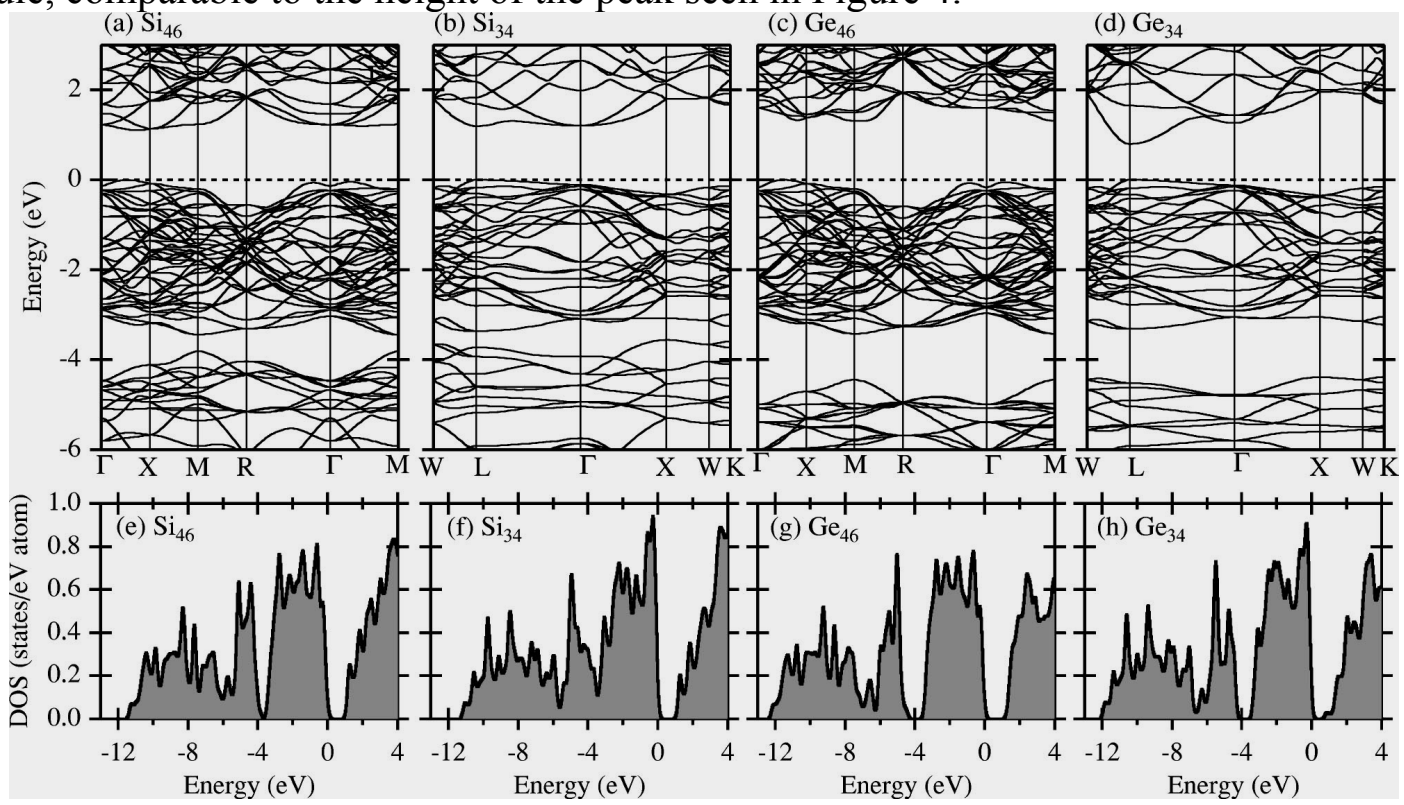

Figure 5: Band structures and electron densities of states calculated for empty $\mathrm{Si}$ and $\mathrm{Ge}$ clathrates [46], using an $a b$ initio pseudopotential method. $\mathrm{Si}_{34}$ and $\mathrm{Ge}_{34}$ are type-II 
clathrates. $\mathrm{Si}_{46}$ and $\mathrm{Ge}_{46}$ are hypothetical empty type-I frameworks. (C) 2000 American Physical Society.

In contrast to the fullerenes, however, the cage-center guest ions in group-IV clathrates hybridize relatively strongly with the framework ions. Calculations for superconducting $\mathrm{Si}_{46}$ clathrates reveal significant $\mathrm{Na}$ and $\mathrm{Ba}$ contributions [43] modifying the conduction band, so that the large $g\left(E_{F}\right)$ can be attributed in part to states of these ions. Similarly in semiconducting $\mathrm{Ba}_{8} \mathrm{Ga}_{16} \mathrm{Ge}_{30}$, and analogs centered by $\mathrm{Sr}$ and $\mathrm{Eu}$, guest-ion $d$-states appear to participate strongly in the conduction band [48]. In type-II $\mathrm{Na}_{x} \mathrm{Si}_{136}$ clathrates, ${ }^{27} \mathrm{Na} \mathrm{NMR}$ shifts have been found to be strongly temperature dependent, indicating the presence of Na-based electron states at $E_{F}$ [49]. Figure 6 shows a theoretical $g(E)$ for this situation; $E_{F}$ appears at a sharp dip in this case rather than the sharp peak as in the type-I case. From the strong presence of $\mathrm{Na}$ states in the band-edge one may make the case that conductivity in $\mathrm{Na}_{x} \mathrm{Si}_{136}$ proceeds via an impurity band, as originally invoked to explain the metal-insulator behavior observed in this material [50]. However this picture seems less apt for the type-I clathrates, for which hybridization between cage-center and framework atoms are generally stronger, and band calculations have generally been successful in modeling the electrical transport behavior.

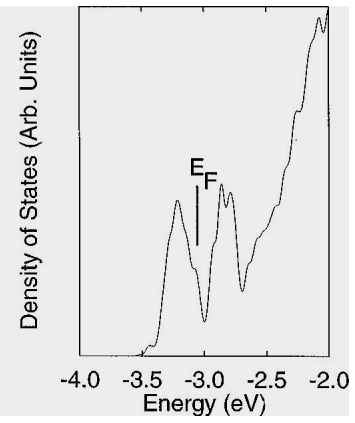

Figure 6: Calculated density of states for type-II $\mathrm{Na}_{8} \mathrm{Si}_{136}$, from [49]. $E_{F}$ appears at an energy just above a strong band of Na-dominated states. (C) 1998 American Physical Society.

\section{Superconducting Mechanism.}

The observation of superconductivity in $\mathrm{Ba}_{8} \mathrm{Si}_{46}$ has led to significant interest in the reason for the relatively large $T_{c}$ in this material. One of the challenges has been the range of reported transition temperatures due to the difficulty of preparing single-phase $\mathrm{Ba}_{8} \mathrm{Si}_{46}$. A study of silicon isotope-substituted samples of $\mathrm{Ba}_{8} \mathrm{Si}_{46}$ [51], however, showed an isotope effect corresponding to the range of expected values for the BCS theory, indicating that a phonon mechanism is responsible for the superconducting state. In addition, by matching the changes in $T_{c}$ due to applied pressure to $a b$ initio calculations [52], a further measure was obtained for the parameters driving superconductivity in the material. In the McMillan theory [53], $T_{c}$ can be expressed,

$$
T_{c}=\frac{\Theta_{D}}{1.45} \exp \left(\frac{-1.04\left(1+\lambda_{e p}\right)}{\lambda_{e p}-\mu^{*}\left(1+0.62 \lambda_{e p}\right)}\right),
$$

where $\Theta_{D}$ is the Debye temperature, and $\lambda_{e p}$ and $\mu^{*}$ are the electron-phonon coupling constant and repulsive interaction, respectively. For $\mathrm{Ba}_{8} \mathrm{Si}_{46}, \lambda_{e p}$ was found to be about 1.05 , and $\mu^{*}$ to be 0.24. The parameter $\lambda_{e p}$ is a product of $g\left(E_{F}\right)$ and the electron pairing interaction, $V_{e p}$. By 
comparison with theoretically calculated values [52], it appears that $g\left(E_{F}\right)$ is the most important parameter determining $T_{c}$.

Further information has been obtained by changing the composition through substitution of framework or cage-center atoms. Table I summarizes the reported changes in $T_{c}$ for such materials. In some cases only the end member of a series is given in this table, for example in Figure 7 is shown the susceptibility for a series $\mathrm{Ba}_{8-x} \mathrm{Sr}_{x} \mathrm{Si}_{46}$ [54], showing the progressive change in $T_{c}$.

Table I: Superconducting transition temperatures as reported in type-I silicon clathrates.

\begin{tabular}{lll}
\hline \hline $\mathrm{Molecular}$ formula & $T_{c}(\mathrm{~K})$ & Reference \\
\hline $\mathrm{Ba}_{8} \mathrm{Si}_{46}$ & 8 & 24 \\
$\mathrm{Ba}_{7.76} \mathrm{Si}_{46}$ & 9 & 25 \\
$\mathrm{Na}_{0.2} \mathrm{Ba}_{6} \mathrm{Si}_{46}$ & 4.8 & 55 \\
$\mathrm{Na}_{0.2} \mathrm{Ba}_{5.6} \mathrm{Si}_{46}$ & 3.5 & 56 \\
$\mathrm{Na}_{0.3} \mathrm{Ba}_{6.2} \mathrm{Si}_{46}$ & 4 & 55 \\
$\mathrm{Na}_{1.5} \mathrm{Ba}_{6} \mathrm{Si}_{46}$ & 2.6 & 55 \\
$\mathrm{Na}_{2 .} \mathrm{Ba}_{4.5} \mathrm{Si}_{46}$ & 4 & 22 \\
$\mathrm{Na}_{8} \mathrm{Si}_{46}$ & 0 & 56 \\
$\mathrm{~K}_{2 .} \mathrm{Ba}_{4.9} \mathrm{Si}_{46}$ & 3.2 & 56 \\
$\mathrm{~K}_{7} \mathrm{Si}_{46}$ & 0 & 56 \\
$\mathrm{Ba}_{2} \mathrm{Sr}_{6} \mathrm{Si}_{46}$ & 4.1 & 54 \\
$\mathrm{Ba}_{8} \mathrm{Si}_{40} \mathrm{Ga}_{6}$ & 3.3 & 57 \\
$\mathrm{Ba}_{8} \mathrm{Si}_{23} \mathrm{Ge}_{23}$ & 2.3 & 26 \\
$\mathrm{Ba}_{8} \mathrm{Cu}_{0.5} \mathrm{Si}_{45.5}$ & 6.3 & 58 \\
$\mathrm{Ba}_{8} \mathrm{Cu}_{4} \mathrm{Si}_{42}$ & 2.9 & 59 \\
$\mathrm{Ba}_{8} \mathrm{Ag}_{0.5} \mathrm{Si}_{45.5}$ & 6.1 & 58 \\
$\mathrm{Ba}_{8} \mathrm{Au}_{1} \mathrm{Si}_{45}$ & 5.8 & 58 \\
\hline \hline
\end{tabular}

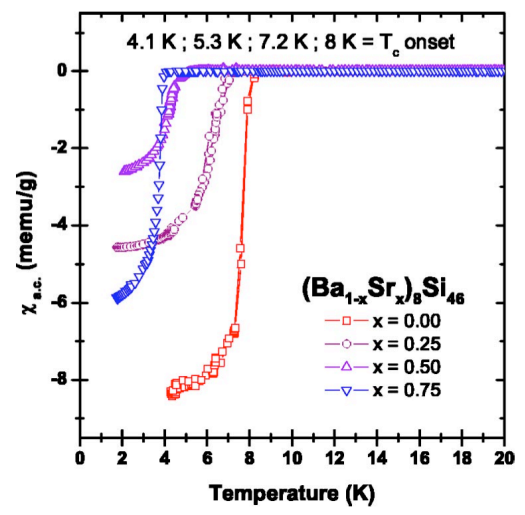

Figure 7: Magnetic susceptibility for $\mathrm{Ba}_{8-x} \mathrm{Sr}_{x} \mathrm{Si}_{46}$ alloys [54], showing the progressive change in $T_{c}$. C 2005 American Physical Society. 
Framework substitutions by fourth-row $\mathrm{Ge}, \mathrm{Ga}$, and $\mathrm{Cu}$ have a progressively larger effect on $T_{c}$, as might be expected from the increasing differences in electronic character relative to Si. A calculated series of electron densities of states [57] (Figure 8) indicates a nearly rigid-band change in the region near $E_{F}$ upon going from $\mathrm{Ba}_{8} \mathrm{Si}_{46}$ to $\mathrm{Ba}_{8} \mathrm{Ga}_{6} \mathrm{Si}_{40}$. The observed change in $T_{c}$ for $\mathrm{Ba}_{8} \mathrm{Ga}_{6} \mathrm{Si}_{40}$ is consistent with a reduction of $\lambda_{e p}$ to 0.78 , attributable to a reduction in $g\left(E_{F}\right)$ of this magnitude, combined with a modest reduction in $V_{e p}$ [57]. Thus it appears that relatively low substitution of $\mathrm{Ga}$ preserves the $s p^{3}$ character of the Si clathrate network. By contrast, a calculated set of electron bands for $\mathrm{Ba}_{8} \mathrm{Cu}_{6} \mathrm{Si}_{40}$, and the corresponding density of states (Figure 9, left), shows a much larger change [59], clearly not rigid-band in character near $E_{F}$.

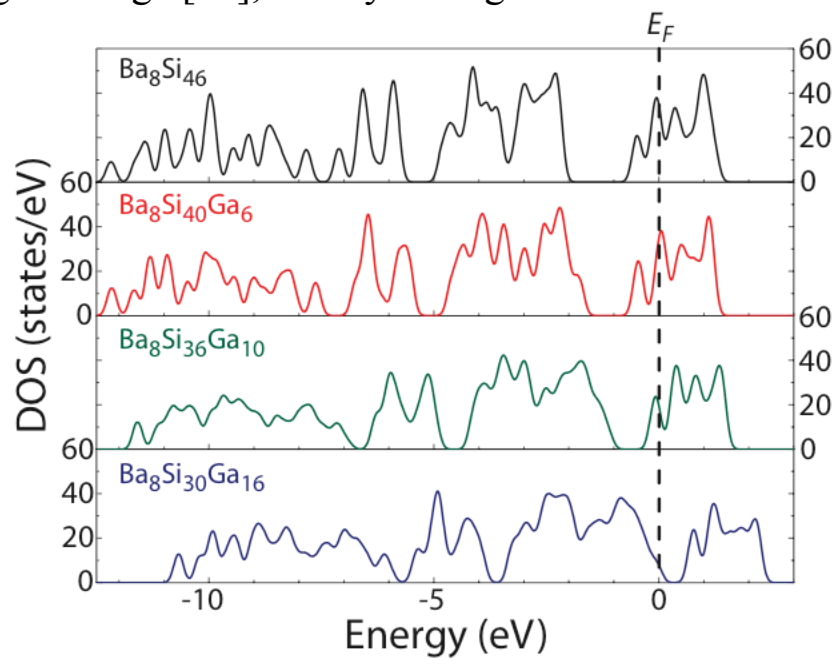

Figure 8: Calculated electron densities of states for Ga-substituted $\mathrm{Ba}_{8} \mathrm{Si}_{46}$ [57]. (C) 2007 American Physical Society.
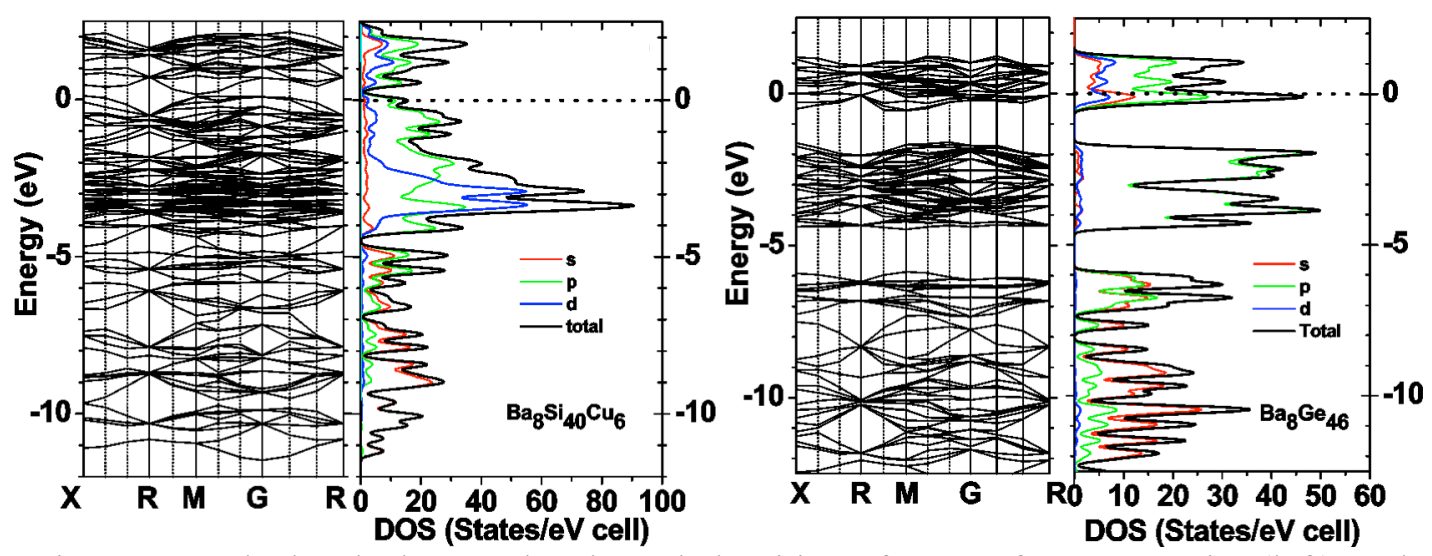

Figure 9: Calculated electron bands and densities of states for $\mathrm{Ba}_{8} \mathrm{Cu}_{6} \mathrm{Si}_{40}$ (left) and hypothetical $\mathrm{Ba}_{8} \mathrm{Ge}_{46}$ [59].

Additional information can be obtained from valence-electron density plots, as in the left panels of Figure 10, for $\mathrm{Ba}_{8} \mathrm{Ga}_{x} \mathrm{Si}_{46-x}$ [57]. Near the top and bottom these sections cut through $\mathrm{Si}-\mathrm{Ga}-\mathrm{Si}$ and Si-Ga-Ga bond sequences, showing that the hybridization of the framework is maintained. The left panels illustrate the Fermi-level resolved states, responsible for the superconductivity, which maintain their integrity for the case $\mathrm{Ba}_{8} \mathrm{Ga}_{6} \mathrm{Si}_{40}$, but become much less well connected for the more highly substituted case. 

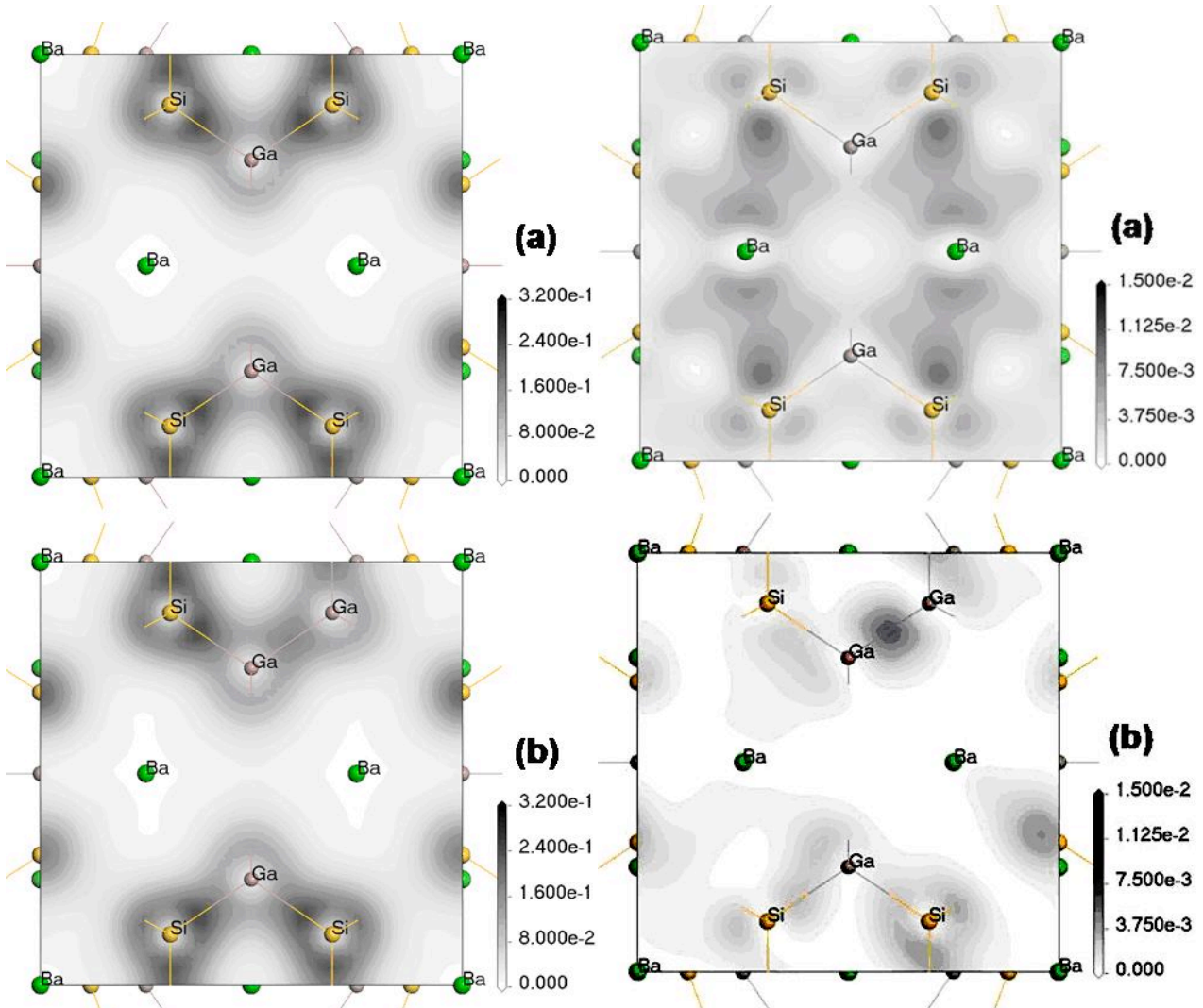

Figure 10: Contour maps of valence-electron densities (left) and Fermi-level-resolved electron densities (right) for: (a) $\mathrm{Ba}_{8} \mathrm{Ga}_{6} \mathrm{Si}_{40}$ and (b) $\mathrm{Ba}_{8} \mathrm{Ga}_{16} \mathrm{Si}_{30}$ [57]. (C) 2007 American Physical Society.

Calculations for Ge-based type-I clathrates (Figure 9, right) indicate an electronic structure for $\mathrm{Ba}_{8} \mathrm{Ge}_{46}$ rather similar to that of $\mathrm{Ba}_{8} \mathrm{Si}_{46}$ [57]; the lack of superconductivity in the former material is due to vacancy formation, as shown below. However there is also likely an increase in $V_{e p}$ going up the periodic table; calculations for a hypothetical type-I carbon clathrate [52] have indicated a significant increase over that observed in silicon clathrates, indicating potentially large increases in $T_{c}$ if such materials could be formed. Among germanium clathrates, there has been only one report of superconductivity, in $\mathrm{Ba}_{8} \mathrm{Ga}_{16} \mathrm{Ge}_{30}$ [60], however most samples of this composition do not show such behavior, which must not be a general property of the material [30].

\section{Zintl concept and Vacancies.}

The Zintl phases [61] are a class of compounds featuring cations from the first or second column combined with more weakly ionic anions from the carbon group or later. In these materials the anions combine to form clusters or connected networks. The combination of electron transfer from the cations and anion-anion hybridization can be viewed as leading to closed-shell configurations in these materials, and hence enhanced stability. The clathrates include classic examples of Zintl phases. For example, in the type-I structure, each framework atom has four framework neighbors. In a localized-bond picture, the hypothetical empty type-I clathrate $\mathrm{Si}_{46}$ would have a closed shell of four bonds per atom, Si having a valence of 4 . In $\mathrm{Ba}_{8} \mathrm{Ga}_{16} \mathrm{Si}_{30}$, the 
presence of 16 valence-3 Ga atoms implies a deficit of 16 bonding electrons per cell. The electron transfer from $8 \mathrm{Ba}$ atoms, each in a nominal $2^{+}$state, can thus achieve a completed bond network. This simplified model has predictive power, and indeed $\mathrm{Ba}_{8} \mathrm{Ga}_{16} \mathrm{Si}_{30}$ is a stable material synthesized more easily than, for example, $\mathrm{Ba}_{8} \mathrm{Si}_{46}$, which has excess framework electrons when viewed in a Zintl picture. Furthermore, the $A_{8} B_{16} \mathrm{Ge}_{30}$ and $A_{8} B_{16} \mathrm{Si}_{30}$ materials $(A=\mathrm{Sr}, \mathrm{Ba}, \mathrm{Eu} ; B$ $=\mathrm{Al}, \mathrm{Ga}$ ) are semiconductors, a hallmark of the Zintl phases, or at most they are very weakly metallic, indicating proximity to a filled-band situation.

$\mathrm{Ba}_{8} \mathrm{Si}_{46}$ exhibits an unbroken framework, as established through crystallography and NMR $[27,62]$. However its analog $\mathrm{Ba}_{8} \mathrm{Ge}_{46}$ does not form a fully populated framework, instead favoring spontaneous vacancy formation $[63,64]$, with the configuration $\mathrm{Ba}_{8} \mathrm{Ge}_{43}$, denoting the vacancies, with a superstructure as shown in Figure 11. According to a Zintl picture four vacancies, with 4 electrons each, might be expected to accept the 16 electrons from $\mathrm{Ba}^{2+}$, completing a network of filled bonds. The observed vacancy count of three may indicate incomplete charge transfer from ionized $\mathrm{Ba}$, or the limitations of the Zintl concept. Type-I alkali metal-tin clathrates exhibit the composition $A_{8} \mathrm{Sn}_{44}{ }_{2}$, in this case precisely satisfying the Zintl criterion [65-67], as does $\mathrm{K}_{8} \mathrm{Ge}_{44} 2$ [68].

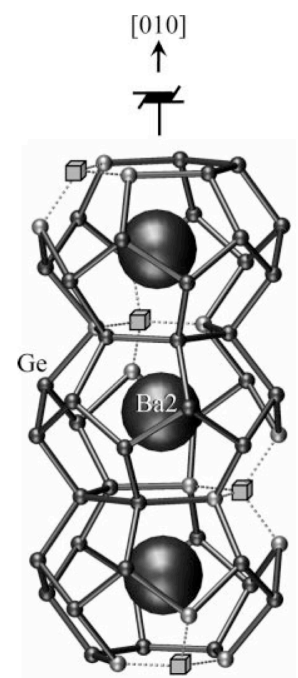

Figure 11: View of the large cages in $\mathrm{Ba}_{8} \mathrm{Ge}_{43}$, with structure based on the type-I structure [64]. Small cubes are vacancies, forming a helical superstructure as shown. (C) 2004 Wiley-VCH.

Germanium and tin clathrates commonly adhere closely to Zintl stability conditions, forming vacancies as needed. For example, the type-I compound initially reported as $\mathrm{Ba}_{8} \mathrm{Cu}_{6} \mathrm{Ge}_{40}$ was found instead to form a composition close to $\mathrm{Ba}_{8} \mathrm{Cu}_{5.3} \mathrm{Ge}_{40.7}$, satisfying the Zintl criterion [69], with $\mathrm{Cu}$ treated as a simple $s-p$ substituent having a valence of 1 . On the other hand, siliconbased $\mathrm{Ba}_{8} \mathrm{Cu}_{x} \mathrm{Si}_{46-x}$ forms with varying composition not keeping to Zintl rules [59,70]. Other germanium and tin clathrates obeying Zintl criteria are $\mathrm{Ba}_{8} \mathrm{Al}_{16-x} \mathrm{Ge}_{30+y}$, which forms vacancies when $x \neq 0$ to maintain a Zintl composition [71], and $\mathrm{I}_{8} \mathrm{Te}_{5.3} \mathrm{Ge}_{40}$ [72], $\mathrm{Sn}_{24} \mathrm{P}_{19.3} \mathrm{I}_{8-y} \mathrm{Cl}_{y}$ [73], and $\mathrm{Sn}_{14} \mathrm{In}_{10} \mathrm{P}_{21.2} \mathrm{I}_{8}$ [74], all exhibiting spontaneous vacancies. $\mathrm{Ba}_{8} \mathrm{Ga}_{10} \mathrm{Si}_{36}$ is the only silicon-based clathrate thus far reported to exhibit spontaneous vacancy formation, [70,75]. On the other hand, $\mathrm{Ba}_{8} \mathrm{Ga}_{6} \mathrm{Si}_{40}$, a composition further from the Zintl phase $\mathrm{Ba}_{8} \mathrm{Ga}_{16} \mathrm{Si}_{30}$, is a bulk superconductor as described above [57], and thus most likely features an unbroken framework. Typically the Si-Si 
bond strength makes vacancy formation less common in silicon-based systems, and although the electronic structures would appear to favor superconductivity in germanium and tin clathrates [59] the tendency of these compounds to form vacancies rather than high-electron compositions explains the lack of superconductivity observed in such materials. It is possible that a highpressure synthesis technique might stabilize a vacancy-free germanium clathrate, but the relatively weak Ge-Ge bond may make this difficult.

\section{Superconductivity in Other Clathrates.}

There are no reports of superconductivity in type-II clathrates, although these materials feature complete $s p^{3}$-bonded frameworks similar to the type-I structure. In part this is because far fewer compositions are found to be stable in the type-II structure. For example there is only one report of a Ba-Si type-II clathrate: $\mathrm{Na}_{16} \mathrm{Ba}_{8} \mathrm{Si}_{136}$ contains $\mathrm{Ba}$ in the larger cage [76], however there has been no superconductivity observed in this compound above $2 \mathrm{~K}$. Among Sn clathrates $\mathrm{Ba}_{16} \mathrm{Ga}_{32} \mathrm{Sn}_{104}$ can be formed with a larger concentration of second-column ions [77,78], although this is a likely Zintl phase with a corresponding low carrier concentration.

By contrast, chiral clathrates have been reported to exhibit superconductivity, for silicon-based and also for germanium-based materials. $\mathrm{Na}_{2} \mathrm{Ba}_{4} \mathrm{Ge}_{25}$ was found to have $T_{c}=0.84 \mathrm{~K}$, and $\mathrm{Ba}_{6} \mathrm{Ge}_{25} T_{c}=0.24 \mathrm{~K}$, under ambient conditions [79]. However, with applied high pressure an increase was observed for $\mathrm{Ba}_{6} \mathrm{Ge}_{25}$ up to $T_{c}=3.8 \mathrm{~K}$ in $2.7 \mathrm{GPa}$ [79]. $\mathrm{Ba}_{6} \mathrm{Ge}_{25}$ is not a Zintl semiconductor, however the eight $s p^{2}$-bonded framework sites per formula unit can formally be regarded to possess lone pairs acting as electron acceptors, so that a Zintl-type charge transfer from $\mathrm{Ba}$ ions to the framework may be regarded as explaining in part its stability [80]. This material exhibits two structural changes under ambient conditions [81] involving shifts of both $\mathrm{Ge}$ and $\mathrm{Ba}$ atoms. The structural distortions induced under high-pressure conditions have been found to be associated with a large increase in $g\left(E_{F}\right)$, which has been identified to be largely responsible for the enhanced $T_{c}$ [82].

Recent reports have also shown that $\mathrm{Ba}_{6} \mathrm{Si}_{25}$ is a superconductor $[83,84]$, with $T_{c}$ as high as 1.55 $\mathrm{K}$ [83]. There is no large pressure-induced change in $\mathrm{Ba}_{6} \mathrm{Si}_{25}$, as observed for $\mathrm{Ba}_{6} \mathrm{Ge}_{25}$, and the complex sequence of structural transitions at ambient conditions is also not present. Thus this material can be compared directly to the corresponding type-I superconductor $\mathrm{Ba}_{8} \mathrm{~S}_{46}$. It is not yet entirely clear why such a large difference is observed between $T_{c}$ for the chiral and type-I BaSi clathrates. The presence of $s p^{2}$-bonded sites in the $s p^{3}$ framework has been invoked as reducing the electron-phonon coupling [83], as have a significant difference in low-frequency vibrational properties [40]. Further study will be needed to resolve this question.

\section{Magnetism.}

The narrow peak in $g\left(E_{F}\right)$ evidenced in $\mathrm{Ba}_{8} \mathrm{Si}_{46}$ might be expected to favor magnetism as well as superconductivity, similar to the $A_{3} \mathrm{C}_{60}$ materials, which are close to a Mott-Hubbard transition. However in both cases, superconductivity is generally preferred. It has been argued that the $s p^{2}$ orbital degeneracy of the fullerenes stabilizes the expanded $\mathrm{C}_{60}$ materials against a metalinsulator transition [85]; similarly the $s p^{3}$ configuration for Si and Ge clathrates may also help to stabilize the superconducting state. As described above, superconductivity in $\mathrm{Ba}_{8} \mathrm{Si}_{46}$ is uniformly suppressed by substitution of transition metals. However this effect has generally been 
shown to be attributable to the broadening of the $g\left(E_{F}\right)$ peak rather than the competing appearance of a magnetic moment.

Ready substitution of transition metals onto the clathrate framework has only been exhibited for late transition elements, starting with $\mathrm{Ni}$. These late transition metals exhibit filled $d$-bands when substituted on the silicon and germanium clathrates, shown for example by the formal valence of 1 for $\mathrm{Cu}$ atoms in the germanium type-I clathrate [69]. The earlier transition metals would be expected to induce magnetic moments, similar to observations in doped III-V and related semiconductors $[86,87]$. The difficulty of substituting earlier transition metals is consistent with diamond-structure silicon, for which the Fe-group atoms are most commonly interstitial rather than substitutional [88]. In addition, there are many competing binary phases among the silicides and germanides. Two examples of substituted magnetic clathrates have been found thus far: type-I $\mathrm{Ba}_{8} \mathrm{Mn}_{2} \mathrm{Ge}_{44}$ [89] and chiral $\mathrm{Ba}_{6} \mathrm{Fe}_{3} \mathrm{Ge}_{22}$ [90]. However these materials are difficult to prepare, for example $\mathrm{Ba}_{6} \mathrm{Fe}_{3} \mathrm{Ge}_{22}$ is apparently stable only at intermediate temperatures. Complicated interrelationships control the stability of such materials [91] it may be that further advances will be made in this direction, for example through stabilization with vacancies.

The largest class of magnetic materials based on the silicon and germanium clathrates occurs with Eu ions occupying cage-filling positions in type-I compounds. In these cases $\mathrm{Eu}^{2+}$ carries a large local moment, leading to a ferromagnetic transition temperature as high as $38 \mathrm{~K}$ for $\mathrm{Eu}_{2} \mathrm{Ba}_{6} \mathrm{Ga}_{8} \mathrm{Si}_{36}$ [92]. The coupling between europium-based magnetic moments is apparently due to an RKKY interaction in all cases, with even the nominally semiconducting Zintl phases having a sufficient residual electron density to allow carrier-intermediated interactions as specified by the RKKY model. It will be interesting to see if the magnetic behavior can be tailored by modifying the carrier concentrations in some of these compounds. The properties of these materials will not be reviewed here, but in Table II we have summarized the compositions reported to exhibit ferromagnetic behavior, along with the reported transition temperatures.

Table II: Eu-containing magnetic clathrates along with reported magnetic transition temperatures. All have type-I structure except for type-VIII $\alpha$ - $\mathrm{Eu}_{8} \mathrm{Ga}_{16} \mathrm{Ge}_{30}$.

\begin{tabular}{lcc}
\hline \multicolumn{1}{c}{ Material } & $T_{c}(\mathrm{~K})$ & Reference \\
\hline $\mathrm{Eu}_{2} \mathrm{Ba}_{6} \mathrm{Ga}_{8} \mathrm{Si}_{36}$ & 38 & 92 \\
$\alpha-\mathrm{Eu}_{8} \mathrm{Ga}_{16} \mathrm{Ge}_{30}$ & 36 & 16 \\
$\mathrm{Eu}_{2} \mathrm{Ba}_{6} \mathrm{Al}_{8} \mathrm{Si}_{36}$ & 32 & 70 \\
$\mathrm{Eu}_{6} \mathrm{Sr}_{2} \mathrm{Ga}_{16} \mathrm{Ge}_{30}$ & 20 & 93 \\
$\mathrm{Eu}_{4} \mathrm{Sr}_{4} \mathrm{Ga}_{16} \mathrm{Ge}_{30}$ & 15 & 93 \\
$\beta-\mathrm{Eu}_{8} \mathrm{Ga}_{16} \mathrm{Ge}_{30}$ & 10.5 & 16 \\
$\mathrm{~K}_{6} \mathrm{Eu}_{2} \mathrm{Cd}_{5} \mathrm{Ge}_{41}$ & 9.3 & 94 \\
$\mathrm{Eu}_{2} \mathrm{Ba}_{6} \mathrm{Cu}_{4} \mathrm{Si}_{42}$ & 5 & 70 \\
$\mathrm{Eu}_{2} \mathrm{Ba}_{6} \mathrm{Cu}_{4} \mathrm{Si}_{38} \mathrm{Ga}_{4}$ & 4 & 70 \\
$\mathrm{~K}_{6} \mathrm{Eu}_{2} \mathrm{Zn}_{5} \mathrm{Ge}_{41}$ & 4 & 94 \\
$\mathrm{~K}_{6} \mathrm{Eu}_{2} \mathrm{Ga}_{10} \mathrm{Ge}_{36}$ & 3.8 & 94 \\
\hline \hline
\end{tabular}

\section{Conclusions:}


Group-IV clathrates are expanded cage-structured materials akin to the fullerenes. However the presence of the extended $s p^{3}$ networks in these materials, as well as the vibrational behavior and Zintl behavior, lead to a number of properties unique to these materials. Here we have discussed the superconducting behavior and shown that the enhanced superconductivity can be regarded as related most strongly to the electronic features of the $s p^{3}$ framework. Charge transfer between cage-center atoms and the framework enhances the stability of these materials, but the Zintl mechanism also limits the ability to design high-carrier density composition, for example promoting spontaneous vacancy formation. In addition because of significant hybridization the cage-center ions participate much more actively in the electronic properties, as compared to carbon-based fullerenes. Magnetism has been observed in a number of cases where framework or cage-center positions can be substituted by magnetic ions.

\section{Acknowledgements:}

This work was supported in part by the Robert A. Welch Foundation (Grant No. A-1526), and the NSF-PREM program (Grant No. 0351449).

\section{References:}

[1] E. D. Sloan Jr. and C. Koh, Clathrate Hydrates of Natural Gases, 3rd ed. (CRC Press, 2007).

[2] E. D. Sloan Jr., Nature 426, 353 (2003).

[3] A. V. Milkov, Earth-Sci. Rev. 66, 183 (2004).

[4] J. S. Loveday and R. J. Nelmes, Phys. Chem. Chem. Phys. 10, 937 (2008).

[5] G. A. Jeffrey, "Hydrate Inclusion Compounds," in Inclusion Compounds, vol. 1, J. L. Atwood, J. E. D. Davies, and D. D. MacNicol, eds. (Academic, London, 1984) p. 135.

[6] H. Gies, "Clathrasils and zeosils: inclusion compounds with silica host frameworks," in Inclusion Compounds, vol. 5, J. L. Atwood, J. E. D. Davies, and D. D. MacNicol eds. (Oxford, 1991), p. 1.

[7] J. S. Kasper, P. Hagenmüller, M. Pouchard, and C. Cros, Science 150, 1713 (1965).

[8] B. Eisenmann, H. Schafer, and R. Zagler. J. Less-Common Met. 118, 43-55 (1986) [S93].

[9] S. Latturner, X. Bu, N. P. Blake, H. Metiu, and G. D. Stucky, J. Solid State Chem. 151, 6164 (2000).

[10] N. Jaussaud, P. Toulemonde, M. Pouchard, A. San Miguel, P. Gravereau, S. Pechev, G. Goglio, and C. Cros, Solid State Sci. 6, 401-411 2004.

[11] G. S. Nolas, T. J. R. Weakley, and J. L. Cohn, Chem. Mater. 11, 2470-2473 (1999).

[12] R. Kroner, R. Nesper, and H. G. von Schnering, Z. Kristallogr. NCS 186, 172 (1989). 
[13] G. Cordier and P. Woll, J. Less-Common Met. 169, 291-302 (1991).

[14] J. Gryko, P. F. McMillan, R. F. Marzke, G. K. Ramachandran, D. Patton, S. K. Deb, and O. F. Sankey, Phys. Rev. B 62, R7707-R7710 (2000).

[15] A. M. Guloy, R. Ramlau, Z. Tang, W. Schnelle, M. Baitinger, and Y. Grin, Nature 443, 320-323 (2006).

[16] S. Paschen, W. Carrillo-Cabrera, A. Bentien, V. H. Tran, M. Baenitz, Yu. Grin, and F. Steglich, Phys. Rev. B 64, 214404 (2001).

[17] R. Kroener, R. Nesper, and H. G. von Schnering, Z. Kristallogr. 182, 164-165 (1988).

[18] H. Fukuoka, K. Ueno, and S. Yamanaka, J. Organomet. Chem. 611, 543-546 (2000).

[19] S. J. Kim, S. Q. Hu, C. Uher, T. Hogan, B. Huang, J. D. Corbett, and M. G. Kanatzidis, J. Solid State Chem. 153, 321-329 (2000); H. Fukuoka, K. Iwai, S. Yamanaka, H. Abe, K. Yoza, and L. Häming, J. Solid State Chem. 151, 117-121 (2000); W. Carrillo-Cabrera, J. Curda, H. G. von Schnering, S. Paschen, Y. Grin, Z. Kristallogr. NCS 216, 172-172 (2001).

[20] T. F. Fässler and C. Kronseder, Z. Anorg. Allg. Chem. 624, 561 (1998).

[21] S. B. Roy, K. E. Sim, and A. D. Caplin, Philos. Mag. B 65, 1445-50 (1992).

[22] H. Kawaji, H. Horie, S. Yamanaka, and M. Ishikawa, Phys. Rev. Lett. 74, 1427-1429 (1995).

[23] S. Yamanaka, H. Horie, and H. Kawaji, Eur. J. Solid State Inorg. Chem. 32, 799-807 (1995).

[24] M. Imai, T. Hirano, T. Kikegawa, and O. Shimomura, Phys. Rev. B 58, 11922-11926 (1998).

[25] H. Fukuoka, J. Kiyoto, and S. Yamanaka, Inorg. Chem. 42, 2933-2937 (2003).

[26] H. Fukuoka, J. Kiyoto, and S. Yamanaka, J. Solid State Chem. 175, 237-244 (2003).

[27] M. Baitinger, H. G. von Schnering, J. H. Chang, K. Peters, and Y. Grin, Z. Kristallogr. NCS 222, 87-88 (2007).

[28] G. S. Nolas and C. A. Kendziora, Phys. Rev. B 62, 7157 (2000).

[29] B. C. Sales, B. C. Chakoumakos, D. Mandrus, and J. W. Sharp, J. Solid State Chem. 146, 528-532 (1999).

[30] B. C. Sales, B. C. Chakoumakos, R. Jin, J. R. Thompson, and D. Mandrus, Phys. Rev. B 63, 245113 (2001).

[31] R. Viennois, P. Toulemonde, M. Koza, H. Mutka, A. San Miguel, and R. Lortz, J. Phys.: Conf. Ser. 92, 012121 (2007). 
[32] C. W. Myles, J. Dong, O. F. Sankey, C. A. Kendziora, and G. S. Nolas, Phys. Rev. B 65, 235208 (2002).

[33] G. A. Slack, MRS Symp. Proc. 478, 47-54 (1997).

[34] V. Keppens, D. Mandrus, B. C. Sales, B. C. Chakoumakos, P. Dai, R. Coldea, M. B. Maple, D. A. Gajewski, E. J. Freeman, and S. Bennington, Nature 395, 876-878 (1998).

[35] R. P. Hermann, V. Keppens, P. Bonville, G. S. Nolas, F. Grandjean, G. J. Long, H. M. Christen, B. C. Chakoumakos, B. C. Sales, and D. Mandrus, Phys. Rev. Lett. 97, 017401 (2006).

[36] J. L. Cohn, G. S. Nolas, V. Fessatidis, T. H. Metcalf, and G. A. Slack, Phys. Rev. Lett. 82, 779-782 (1999).

[37] W. Gou, Y. Li, J. Chi, J. H. Ross Jr., M. Beekman, G. S. Nolas, Phys. Rev. B 71, 174307 (2005).

[38] R. Baumbach, F. Bridges, L. Downward, D. Cao, P. Chesler, B. Sales, Phys. Rev. B 71, $024202(2005)$.

[39] A. Bentien, M. Christensen, J. D. Bryan, A. Sanchez, S. Paschen, F. Steglich, G. D. Stucky, and B. B. Iversen, Phys. Rev. B 69, 045107 (2004).

[40] J. S. Tse, T. Iitaka, and K. Parlinski, Europhys. Lett. 75, 153-159 (2006).

[41] J. S. Tse, K. Uehara, R. Rousseau, A. Ker, C. I. Ratcliffe, M. A. White, and G. MacKay, Phys. Rev. Lett. 85, 114 (2000).

[42] K. Moriguchi, M. Yonemura, A. Shintani, and S. Yamanaka, Phys. Rev. B 61, 9859-9862 (2000).

[43] S. Saito and A. Oshiyama, Phys. Rev. B 51, 2628-2631 (1995).

[44] T. Yokoya, A. Fukushima, T. Kiss, K. Kobayashi, S. Shin, K. Moriguchi, A. Shintani, H. Fukuoka, and S. Yamanaka, Phys. Rev. B 64, 172504 (2001).

[45] H. Sakamoto, H. Tou, H. Ishii, Y. Maniwa, E. A. Reny, and S. Yamanaka, Physica C 341, 2135-2136 (2000).

[46] K. Moriguchi, S. Munetoh, and A. Shintani, Phys. Rev. B 62, 7138-7143 (2000).

[47] R. M. Fleming, A. P. Ramirez, M. J. Rosseinsky, D. W. Murphy, R. C. Haddon, S. M. Zahurak, and A. V. Makhija, Nature 352, 787 (1991).

[48] G. K. H. Madsen, K. Schwarz, P. Blaha, and D. J. Singh, Phys. Rev. B 68, 125212 (2003).

[49] J. Gryko, P. F. McMillan, R. F. Marzke, A. P. Dodokin, A. A. Demkov, and O. F. Sankey, Phys. Rev. B 57, 4172 (1998).

[50] N. F. Mott, J. Solid State Chem. 6, 348-351 (1973). 
[51] K. Tanigaki, T. Shimizu, K. M. Itoh, J. Teraoka, Y. Moritomo, and S. Yamanaka, Nature Mater. 2, 653-655 (2003).

[52] D. Connétable, V. Timoshevskii, B. Masenelli, J. Beille, J. Marcus, B. Barbara, A. M. Saitta, G.-M. Rignanese, P. Mélinon, S. Yamanaka, and X. Blase, Phys. Rev. Lett. 91, 247001 (2003).

[53] W. L. McMillan, Phys. Rev. 167, 331 (1968).

[54] P. Toulemonde, C. Adessi, X. Blase, A. San Miguel, and J. L. Tholence, Phys. Rev. B 71, 094504 (2005).

[55] H. Kawaji, K. Iwai, and S. Yamanaka, Solid State Commun. 100, 393-395 (1996).

[56] S. L. Fang, L. Grigorian, P. C. Eklund, G. Dresselhaus, M. S. Dresselhaus, H. Kawaji, and S. Yamanaka, Phys. Rev. B 57, 7686-7693 (1998).

[57] Y. Li, R. Zhang, Y. Liu, N. Chen, Z. P. Luo, X. Ma, G. Cao, Z. S. Feng, C.-R. Hu, and J. H. Ross Jr., Phys. Rev. B 75, 054513 (2007).

[58] R. F. W. Herrmann, K. Tanigaki, S. Kuroshima, and S. Kuroshima, Chem. Phys. Lett. 283, 29 (1998).

[59] Y. Li, Y. Liu, N. Chen, G. Cao, Z. Feng, J. H. Ross Jr., Phys. Lett. A 345, 398 (2005).

[60] J. D. Bryan, V. I. Srdanov, G. D. Stucky, and D. Schmidt, Phys. Rev. B 60, 3064-7 (1999).

[61] S. M. Kauzlarich, ed., Chemistry, structure, and bonding of Zintl phases and ions (VCH, New York, 1996).

[62] G. K. Ramachandran, P. F. McMillan, J. Diefenbacher, J. Gryko, J. Dong, and O. F. Sankey, Phys. Rev. B 60, 12294-12298 (1999).

[63] R. F. W. Herrmann, K. Tanigaki, T. Kawaguchi, S. Kuroshima, and O. Zhou, Phys. Rev. B 60, 13245 (1999).

[64] W. Carrillo-Cabrera, S. Budnyk, Y. Prots, and Y. Grin, Z. Anorg. Allg. Chem. 630, 2267 (2004).

[65] J.-T. Zhao and J. D. Corbett, Inorg. Chem. 33, 5721 (1994).

[66] F. Dubois and T. F. Fässler, J. Am. Chem. Soc. 127, 3264-3265 (2005).

[67] A. Kaltzoglou, S. D. Hoffmann, and T. F. Fässler, Eur. J. Inorg. Chem. 2007, 4162-4167 (2007).

[68] G. K. Ramachandran and P. F. McMillan, J. Solid State Chem. 154, 626-634 (2000).

[69] Y. Li, J. Chi, W. Gou, S. Khandekar, and J. H. Ross Jr., J. Phys.: Condens. Matter 15, 5535 (2003). 
[70] Y. Mudryk, P. Rogl, C. Paul, S. Berger, E. Bauer, G. Hilscher, C. Godart, and H. Noel, J. Phys.: Condens. Matter 14, 7991-8004 (2002).

[71] C. L. Condron, S. M. Kauzlarich, F. Gascoin, and G. J. Snyder, Chem. Mater. 18, 49394945 (2006).

[72] K. A. Kovnir, N. S. Abramchuk, J. V. Zaikina, M. Baitinger, U. Burkhardt, W. Schnelle, A. V. Olenev, O. I. Lebedev, G. Van Tendeloo, E. V. Dikarev, and A. V. Shevelkov, Z. Krist. 221, 527-532 (2006).

[73] J. V. Zaikina, W. Schnelle, K. A. Kovnir, A. V. Olenev, Y. Grin, and A. V. Shevelkov, Solid State Sci. 9, 664 (2007).

[74] M. M. Shatruk, K. A. Kovnir, M. Lindsjö, I. A. Presniakov, L. A. Kloo, and A. V. Shevelkov, J. Solid State Chem. 161, 233-242 (2001).

[75] D. Nataraj and J. Nagao, J. Solid State Chem. 177, 1905-1911 (2004).

[76] T. Rachi, K. Tanigaki, R. Kumashiro, J. Winter, and H. Kuzmany, Chem. Phys. Lett. 409, 48-51 (2005).

[77] A. Czybulka, B. Kuhl, and H.-U. Schuster, Z. Anorg. Allg. Chem. 594, 23-28 (1991).

[78] R. Kroner, K. Peters, H. G. von Schnering, and R. Nesper, Z. Kristallogr. NCS 213, 664 (1998).

[79] F. M. Grosche, H. Q. Yuan, W. Carrillo-Cabrera, S. Paschen, C. Langhammer, F. Kromer, G. Sparn, M. Baenitz, Yu. Grin, and F. Steglich, Phys. Rev. Lett. 87, 247003 (2001).

[80] H. G. von Schnering, A. Zurn, J. H. Chang, M. Baitinger, and Y. Grin, Z. Anorg. Allg. Chem. 633, 1147-1153 (2007).

[81] W. Carrillo-Cabrera, H. Borrmann, S. Paschen, M. Baenitz, F. Steglich, and Y. Grin, J. Solid State Chem. 178, 715-728 (2005).

[82] H. Q. Yuan, F. M. Grosche, W. Carrillo-Cabrera, V. Pacheco, G. Sparn, M. Baenitz, U. Schwarz, Y. Grin, and F. Steglich, Phys. Rev. B 70, 174512 (2004).

[83] R. Viennois, P. Toulemonde, C. Paulsen, and A. San-Miguel, J. Phys.: Condens. Matter 17, L311-L319 (2005).

[84] T. Rachi, H. Yoshino, R. Kumashiro, M. Kitajima, K. Kobayashi, K. Yokogawa, K. Murata, N. Kimura, H. Aoki, H. Fukuoka, S. Yamanaka, H. Shimotani, T. Takenobu, Y. Iwasa, T. Sasaki, N. Kobayashi, Y. Miyazaki, K. Saito, F. Z. Guo, K. Kobayashi, K. Osaka, K. Kato, M. Takata, and K. Tanigaki, Phys. Rev. B 72, 144504 (2005).

[85] P. Durand, G. R. Darling, Y. Dubitsky, A. Zaopo, and M. J. Rosseinsky, Nature Mater. 2, 605 (2003).

[86] S. Picozzi, Nature Mater. 3, 349 (2004). 
[87] T. Jungwirth, J. Sinova, J. Mašek, J. Kučera, and A. H. MacDonald, Rev. Mod. Phys. 78, 809 (2006).

[88] K. A. Kikoin and V. N. Fleurov, Transition Metal Impurities in Semiconductors (World Scientific, Singapore, 1994).

[89] T. Kawaguchi, K. Tanigaki, and M. Yasukawa, Appl. Phys. Lett. 77, 3438 (2000).

[90] Y. Li and J. H. Ross Jr., Appl. Phys. Lett. 83, 2868 (2003).

[91] P. Mahadevan and A. Zunger, Phys. Rev. Lett. 88, 047205 (2002).

[92] Y. Mudryk, P. Rogl, C. Paul, S. Berger, E. Bauer, G. Hilscher, C. Godart, H. Noel, A. Saccone, and R. Ferro, Physica B 328, 44 (2003).

[93] G. T. Woods, J. Martin, M. Beekman, R. P. Hermann, F. Grandjean, V. Keppens, O. Leupold, G. J. Long, and G. S. Nolas, Phys. Rev. B 73, 174403 (2006).

[94] S. Paschen, S. Budnyk, U. Kohler, Y. Prots, K. Hiebl, F. Steglich, and Y. Grin, Physica B 383, 89 (2006). 